\title{
Gender Norms and Family Planning Decision-Making Among Married Men and Women, Rural Ethiopia: A Qualitative Study
}

\author{
Dereje Geleta $^{1}$, Zewdie Birhanu ${ }^{2}$, Michelle Kaufman ${ }^{3}$, Bezawit Temesgen ${ }^{4}$ \\ ${ }^{1}$ Department of public Health, College of Medicine and Health Sciences, Adigrat University, Adigrat, Ethiopia \\ ${ }^{2}$ Department of Health Education and Behavioral Science, Jimma University, Jimma, Ethiopia \\ ${ }^{3}$ Johns Hopkins Bloomberg School of Public, Department of Health, Behavior and society, Baltimore, USA \\ ${ }^{4}$ Department of Health Education and Behavioral Science, Jimma University, Jimma, Ethiopia
}

\section{Email address:}

darajegalata@gmail.com (D. Geleta), zbkoricha@yahoo.com (Z. Birhanu), michellekaufman@jhu.edu (M. Kaufman), bezawitnew@yahoo.com (B. Temesgen)

\section{To cite this article:}

Dereje Geleta, Zewdie Birhanu, Michelle Kaufman, Bezawit Temesgen. Gender Norms and Family Planning Decision-Making Among Married Men and Women, Rural Ethiopia: A Qualitative Study. Science Journal of Public Health. Vol. 3, No. 2, 2015, pp. $242-250$. doi: $10.11648 /$ j.sjph.20150302.23

\begin{abstract}
Family planning service contributes a lot in reduction of morbidity and mortality and it does more help couples to limit the number of their children. Women's ability to control her on fertility strongly affected by social constructs of Gender role, expectations and gender inequalities. Objective: To explore influence of gender norms on family planning decisionmaking among married men and women, rural Ethiopia, 2013. Methods: A qualitative study using grounded approach was employed. Data collection included in-depth interview with key informants and focus group discussion as conducted with both married women and married men. Interview was done using a semi-structured interview guide with open-ended questions. Axial coding was employed. Codes were aggregated and memos are developed. Result: Different gender norms in the community were obstacles for family planning utilization in the community. Those different gender norms directly or being by complement with each other acts as the barriers of FP utilizations. Decision making power of men/husbands on family planning (needs for his consent by women/wives), seeing children as social prestige due to cultural beliefs, low status of women in community, undermine knowledge of women, limiting responsibility of women/wives to home, dominance of men/husbands on households, etc. Conclusion: Due to men's dominance at the household level and other related factors, the role of women on family planning decision making was limited to merely accepting the decisions of their husbands. Furthermore due to men's power of decision making the final decision was made based on the men's interest.
\end{abstract}

Keywords: Gender Norms, Qualitative Research, Grounded Theory, Family Planning Decision Making

\section{Background}

Family planning service contributes to:-The reduction of morbidity and mortality of mothers and children, Avert unplanned pregnancy and its adverse consequence that is high risk abortion, Prevention of HIV/AIDS and other sexually transmitted diseases, Improved standard of living, Increase of house hold income; and promotes the conservation and efficient use of natural resources $(1,2)$.

Family planning does more than help women and couples limit the size of their families: It safeguards individual health and rights, preserves natural resources, and can improve the economic outlook for families and communities $(1,2)$.
In sub-Saharan Africa as a whole, only 17 percent of married women are using contraceptives, as against 50 per cent in North Africa and the Middle East, 39 per cent in South Asia, 76 per cent in East Asia and the Pacific and 68 per cent in Latin America and the Caribbean. Only in a few countries, such as South Africa, Zimbabwe, Botswana, and Kenya, have family planning programs been successful enough to increase contraceptive use to much higher levels (3).

Family planning services were introduced in Ethiopia in 1948. Although at the beginning the services were limited to 
only major cities, gradually the services expanded to the rural areas and are being used now by the rural communities(4).

The Government of Ethiopia is committed to achieving Millennium Development Goal 5 (MDG5), to improve maternal health, with a target of reducing the maternal mortality ratio (MMR) by three-quarters over the period 1990 to 2015. Accordingly, the Federal Ministry of Health (FMOH) has applied multi-pronged approaches to reducing maternal and newborn morbidity and mortality (5).

Adverse consequences of low provision family planning, Increase of maternal mortality due to unwanted pregnancy and illegal abortion, Hinders mothers from participating in developmental activities, Children don't grow properly due to lack of appropriate care and affection by parents, Children are exposed to illnesses and deaths due to the lack of appropriate care from parents.

Children and the rest of the family members don't receive adequate health and other social services and Unfavorable impact on the economic status of a family to provide appropriate care to children's growth and development $(4,5)$

Unequal power relations, especially in more patriarchal societies, may confound decisions about contraceptive use and childbearing. Studies in Ethiopia showed that because of the male dominance in the culture, women are often forced to bear large number of children $(6,7)$

Despite the fact that FP services are made accessible nearly at all major urban areas in Ethiopia and in most instances at low or no cost, the decisions that lead women to use the services seems to occur within the context of their marriage, household and family setting(8)

\section{Literature Review}

As studies have shown Worldwide Gendered social expectations have many implications for women and men's reproductive lives. A social norm favors male children and promoting women's economic dependence on men. Inability to negotiate sex, condom use, or monogamy on equal terms leaves women and girls worldwide at high risk of unwanted pregnancy, illness and death from pregnancyrelated causes, and sexually transmitted infections(9)

According to the Men and gender equality policy project report, survey research with men and boys in numerous settings of African countries has shown how inequitable and rigid gender norms influence men's practices on a wide range of issues, including contraceptive use and health seeking behavior (10)

As study in Ethiopia showed because of the male dominance in the culture, women are often forced to bear a large number of children. Better knowledge, fear of a partner's opposition or negligence, involvement in decisions about child and economic affairs were statistically significant factors for better decision making power of women on the use of modern contraceptive methods in the rural part (11)

Attitude, Beliefs and Perception of Men to Ward Family Planning

The finding from study done in Kenya showed that when new clients were asked to give a single reason for their choice of specific family planning method, most reported the attitudes of their spouse or their peers(15)

Findings on what partners know about each other's views and preferences show that there is often little communication, even within long-standing relationships. Improving men's understanding of their own motivations, fears and desires, their ability to broach topics relating to sexuality, and their respect for their partners' wishes is central to improving reproductive health(16)

Many men are poorly informed regarding sexuality and reproduction and need guidance on how to share decision making and negotiate on how choices with their partners. About $10 \%$ of Kenyan married couples are using a method that requires male participation, such as condom, periodic abstinence, withdrawal, or vasectomy (17)

\section{Methods}

\subsection{Study Design}

A qualitative study with grounded theory was employed.

\subsection{Inclusion and Exclusion Criteria}

\subsubsection{Inclusion Criteria}

All married couples of reproductive age (age $15-49$ years) that were living in the study area.

\subsubsection{Exclusion Criteria}

Those divorced and widowed.

Respondents who were severely ill and cannot provide adequate information during data collection.

\subsection{Sample Size and Sampling Techniques}

\subsubsection{Sample Size}

The sampling technique focuses to involve various stakeholders who can reflect the different inputs required to meet the set objective. A total of 8 FGDs, 4 with married men and 4 with married women were conducted. Two FGDs were conducted for each selected Kebele. One with married women and one with married men. For each FGD, 7-10 individuals were selected.

Married men: married men among the selected Kebeles were participated on FGD. 8-10 Married men were participated from the selected rural Kebele.

Married women: married women among the selected Kebeles were participated on FGD. 7-9 Married women were participated from the selected rural Kebele.

\subsubsection{Participant Selection}

The researcher was discussed and consulted with the different Woreda focal personnel, as to the most efficient ways, to recruit potential participants. The researcher was developed the recruitment guidelines that explained the procedure briefly to the participants.

\subsubsection{Sampling Method}

Purposive sampling was employed. The participants were 
selected on the criteria to meet the objective and research question of the study. For FGD, participants were expected to be married men/women, formal resident of the kebele, includes ever user, current user and non-user regarding family planning status. This criterion was used for both married men and women for FGD. Key informants were selected based on the knowledge and exposure they have in relation to the topic of the study.

\subsubsection{Data Collection Process}

The data collection process was done using semistructured interview guides with open-ended questions. Both in - depth interviews and FGDs was employed and audio recorded.

\subsection{Data Collection Method}

As data collection method two most common methods of data collection in qualitative study was employed. The methods employed were in-depth interview and focus group discussion.

\subsubsection{In- Depth Interview Participants}

A total of 14 in-depth interviews were conducted among the selected key informants. The selected key informants for the study were woreda family planning focal personnel(1), woreda women's and children's affairs(1), Health extension workers(4), Religion leaders(4) and kebele women's federation (4).The interview was conducted face-to-face and involved one interviewer and one participant.

\subsubsection{Data Management and Analysis Procedure}

Transcription headers with basic information about an interview participant were added to each transcript. All notes and audio recordings were transcribed in to Afaan Oromo (all IDI and FGDs) then translated to English by the principal investigator immediately after data collection.

Following the transcription, axial coding was employed. Those Codes were aggregated and the concepts were defined, and memos were elaborated to the concepts developed by the researcher. Conceptualization of the data was done using the memos. To manage the overall coding and memo developing process ATLAS.ti -7 software was used.

\section{Result}

\subsection{Focus Group Discussion Participants}

A total of 67 (35 men and 32 women) respondent were participate in focus group discussion. Table- 2 presents socio demographic characteristics of FGD participants.

Table-1. Socio-demographic characteristics of FGD participants, rural Ethiopia, June 2013.

\begin{tabular}{|c|c|c|c|c|c|}
\hline & & \multicolumn{2}{|l|}{ Men } & \multicolumn{2}{|l|}{ Women } \\
\hline & & Frequency & Percent & frequency & Percent \\
\hline \multirow{2}{*}{ Religion } & Orthodox & 18 & 51.4 & 15 & 46.9 \\
\hline & Protestant & 17 & 48.6 & 17 & 53.1 \\
\hline \multirow{2}{*}{ Educational status } & Illiterate & 17 & 48.6 & 21 & 65.6 \\
\hline & Read and write & 18 & 51.4 & 11 & 34.4 \\
\hline \multirow{3}{*}{ FP status } & Current user & 10 & 28.6 & 8 & 25.0 \\
\hline & Ever user & 3 & 8.6 & 3 & 9.4 \\
\hline & Non-user & 22 & 62.8 & 21 & 65.6 \\
\hline \multirow{4}{*}{ Ranges of number of children } & $1-4$ & 9 & 25.7 & 14 & 43.8 \\
\hline & $5-8$ & 13 & 37.1 & 7 & 21.9 \\
\hline & $9-12$ & 11 & 31.4 & 10 & 31.2 \\
\hline & $12^{+}$ & 2 & 5.8 & 1 & 3.1 \\
\hline \multirow{3}{*}{ Age ranges } & $20-34$ & 9 & 25.7 & 19 & 59.4 \\
\hline & $35-44$ & 17 & 48.6 & 13 & 40.6 \\
\hline & $45-54$ & 9 & 25.7 & & \\
\hline
\end{tabular}

* Men's contraceptive status refers to their partner's.

\subsection{Prevalent Gender Norms}

The study revealed that gender norms practice in the community begins early at birth. Cultural belief accepted from previous generation, beliefs and attitude related to gender and lack of education was stated as the main pre- existing conditions for gender norms in the community. Religion is not considered as support of gender norms and almost all participants said religion they follow never support gender norms. 


\subsection{Effects of Gender Norms on Women}

Gender norms in the community give low social status for women. A man is the sole decision-maker, and it doesn't matter whether the woman has her views or not. Men want to have the first and last word on their household.

One participant said

“...: women cooks, fetch water, goes mail house, collect wood, make coffee, care children, wash clothes, etc. in addition to all this activities during farming session and harvest session she works on field equally with men. Tonight after field work men can sleep but the women cannot get any rest. She cooks dinner, fetches water, makes coffee, wash children, etc. she is so busy with home work up to midnight or more. again she awake up to early before husband and make breakfast, coffee, fetch water, still he will sleep and awake up when everything was ready. Women have no rest all the day...." ( 36 yrs old Men FGD, Osole kebele).

As stated in above quotes both men and women know that the problem related with gender norm on health of women.

All home works those are so difficult and known they have an effect on health of women are seen as responsibility of women. Both men and women accept this one.

The idea given by woreda women's and children supports this idea.

"...In rural community women spent most of their time in home. Women are working 17-18 hours per day as our woreda. This shows how much burden was on each woman. She awake up early before her husband and slept after midnight. Women have no time to take rest each day." (Head, Woreda women's and children's affairs)

In the community it believed universally in all kebele homework is for women. Due to this believes the community have different attitude to works and it leads to work division among men and women.

\subsection{Pre- Existing Conditions those Support Gender Norms in Community}

Cultural beliefs and attitude toward gender are stated as the major factors those play crucial role in the existence of gender norms in the community. Participant said that different proverbs and sayings those highly express different gender norms in community are all those accepted from the previous generation.

Gender norms in the community are long lasting and deep rooted within the life of the community. Most of them are considered as it was given by God and universally accepted on the world.

The head, woreda women's and children's affairs said

"...It is common that most of the norms are those come from previous generation. So they deeply rooted in the day to day life of this community. It is accepted as a culture and beliefs of this community. It is rare to see when women complain or protest the activities of her husband" (Head woreda, women's and children's affairs)

As stated from all participants and religion leaders of both religion there is no difference between men and women according to their religion views and their doctrine. One of the religion leaders said

"...my religion is protestant and I am an evangelical. As our religion view or doctrine women and men are equal. That was stated in Holly bible... gender norms in community are highly related with cultural beliefs and attitude toward gender of the community.... Lack of education is also another factor. Majority of this community have no education background and they live as the culture and beliefs of previous generation" (Religion leader, protestant, Chanco Kebena)

\subsection{Family Planning Decision Making Process/Manner}

Decision on family planning between married couples is not familiar as participants Reports. Woreda family planning focal personnel, woreda women's and children's affairs and HEWs are highly related the decision between married men and women with gender norms in the community.

In addition the main problem stated by almost all participants, there is disagreement or interest gap between the couples on family planning.

One participants of FGD said

" even if couples (married men and women) discuss on the family planning the family decision made was based on the interest of husband. Most of men or husband assume as they were defeated or lose acceptance if they were accept the idea of their wives. He will never give any responsibility in community. He assumed as the one who cannot lead his house/wife. All this makes men aggressive and protestors towards the interest of their wife. (28 yrs old, Men FGD Osole kebele)

The decision making power of women in the community is almost none. Always women are under the control of their husband. That norm is directly play a crucial role on the decision making process on family planning among the couples.

\subsection{Cultural Beliefs Related to Number of Children}

Men's need for more children as social prestige, fear of side effects, misconception and rumors related with methods and lack of decision making power of women are among the most stated challenges regarding poor utilization of family planning among married men and women. Men are highly expected to get child after married. One male of FGD participant said that

".... The attitude of men toward lots of children still not changed. Men believe that their name was called by their children so they wants to got a lot of children in order to be popular men in community by their children. They are assumed as a source of pride. (47 yrs old Men, FGD Osole kebele)

The above quote shows cultural belief and attitude toward children in community regarding men/husband. Having child early after the marriage was what expected from the husband.

In community there is a cultural beliefs of family with 
many children has less risk of being physically attacked by another family than a family with a small number of children. One participant of FGD said

" let tell you a story that I know. My grandfather is the only child for his family. So he said he was attacked by the children of those from large family (those have many brothers and sisters) and people do not respect him due to he has no brother and sister. Then he got married and got my father and told him to have a lot of children. Then my father married four women and now he has 32 children including me. Now our family his high respected in community and no one want to make any conflict with our family. In case of any problem we are fight over each other..." (30 yrs oldMen.FGD Tullu Gurji kebele)

Some participants both men and women stated needs for more children is not only by men but also there are women those want to have more children.

\subsection{Final Decision Making on FP and Role of Women}

In the community final decision on family planning was made by the husband. Only few couples were deciding the method by discussion.

If women/wives are against the interest of their husband they will be divorced or the men go to other women to get children. Once the women were divorced it is impossible or very difficult for them to get married again. But men can marry another women without any difficult at any time. One participant said that

"Husband is final decision maker... If she is refused he does not care about her. In our community the divorced women was not respected and other men also not interested to marry. So without her interested but due to fear of divorced the wife was enforced to fulfill the interest of her husband. (35 yrs old Men, FGD, Tullu Gurji Kebele)

\subsection{Using Family Planning by Secret and its Consequence}

Magnitude of using family planning by secret was high and common among married women in the community. The main reason which leads the women to use the method by secret was due to rejection of their need of using family planning by their husbands.

. One participants of FGD said that

" it is common. A Number of women using by secret is not small number if you compare it with those use it formally. The main reason for this is that husbands never want his wife to use family planning. It assumed as a duty of wife to give birth."(34 yrs old Men, FGD Osole kebele)

For those women using the method by secret injection/DEPO was their method of choice.

\subsection{Family Planning Decision Making and Gender Norm}

In the community there are different norms related directly with gender. The ways women grow up in their family has great impact on their decision making power. From their early childhood daughters are commanded to accept what was said by their father and brothers. Also they are not permitted to go out of the home and protected to speak in front of men.

Family planning decision making process between married men and women was directly related with those gender norms. Women believe that they must obey what was said by their husband. One FGD participant said

"Yes of course. As we discussed before women cannot do want they want as men do. If she wants to quit or space a birth it must also the interest of her husband. Unless it is a interest of the husband, it is impossible for women to use family planning. This due to women is under the control of her husband. (40 yrs old Men, chanco kebele)

Table-2. Summary of Gender norms that discourage family planning utilization, in rural Ethiopia,June 2013.

\begin{tabular}{|c|}
\hline Gender norms \\
\hline The low social status of women in community \\
\hline Superiority of men in community \\
\hline Men dominance in house holds \\
\hline Women are under control of husband \\
\hline $\begin{array}{l}\text { Pre-existing condition(beliefs, attitude and proverbs/sayings related to } \\
\text { genders) }\end{array}$ \\
\hline Undermines the knowledge of women \\
\hline Limits the responsibility of women to home \\
\hline Considers women as weak nature \\
\hline Couples communications and Decision making power \\
\hline The man/husband makes final decision in households \\
\hline It is disrespectful for women to disagree with her husband \\
\hline The husband manages the resource and use it as much and any time \\
\hline Women wants the permission of husband to use resource \\
\hline Family planning decision making \\
\hline The man/husband decides whether to use or not use family planning \\
\hline Men's dominance on final decision making on FP \\
\hline Women shouldn't use family planning without her husband's consent \\
\hline Fear of side effects, misconception and rumours to FP \\
\hline Child bearing and family size \\
\hline Large family is given social prestige or popularity \\
\hline Men needs more children \\
\hline Relatives and neighbours influence couples to have more children \\
\hline
\end{tabular}




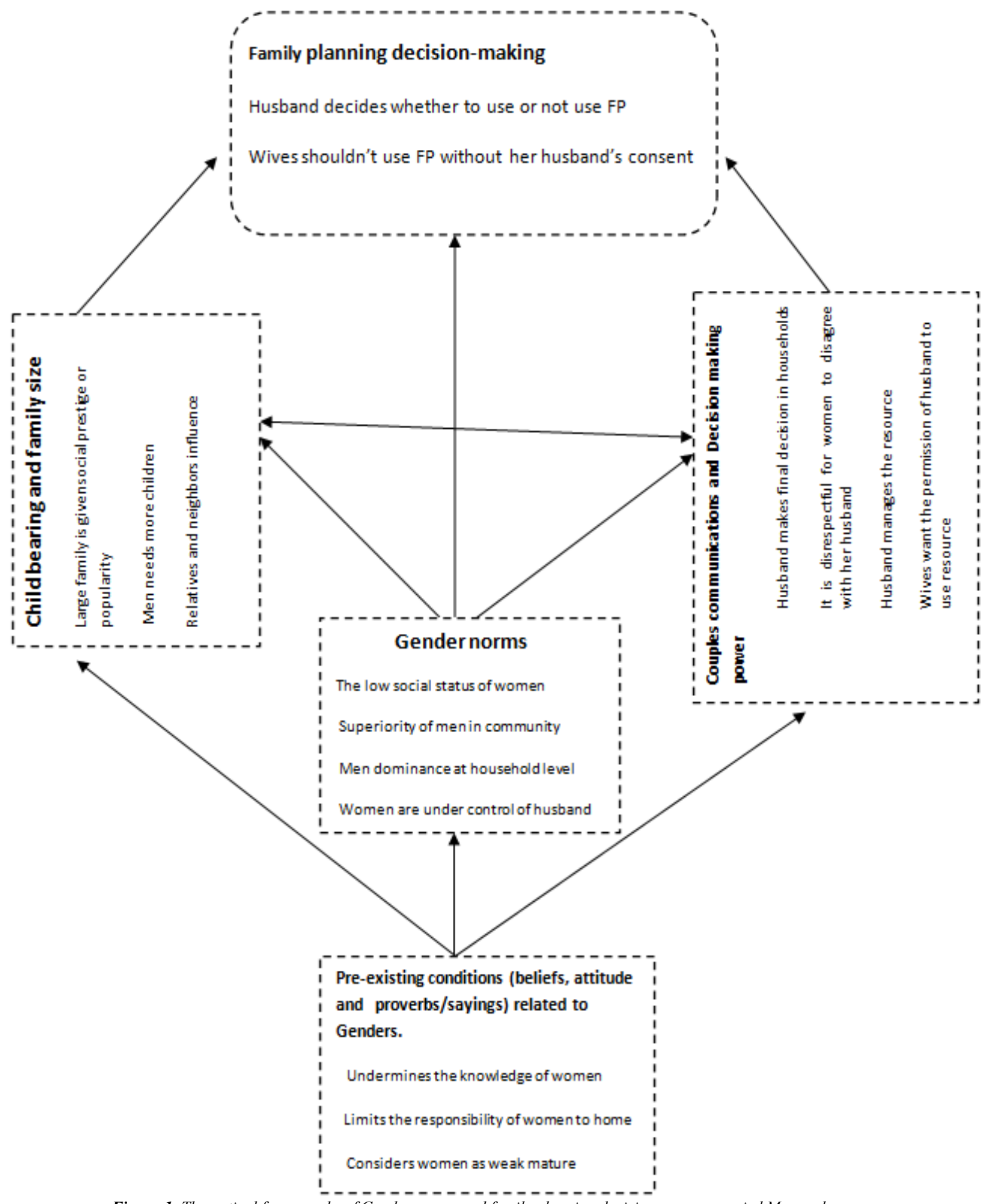

Figure-1. Theoretical frameworks of Gender norms and family planning decision among married Men and women.

From the study it was found that Beyond the complexity of gender norms in the community they put men/husband and women/wives in opposite direction. Which means attitudes and beliefs about both genders are in community was always opposite to each other. What was supposed for men is forbidden for women and the vise- versa. It is obvious that the gender norms in the community were very complicated and influenced by different factors. So this was used make the conceptualization less complicated and easy to understand.

The conceptualization was made from two views. First, gender norms on the side of men/husband identity (masculinity) and second were on side of women/wives (femininity) identity in the community. 
See the following conceptualization figure below.

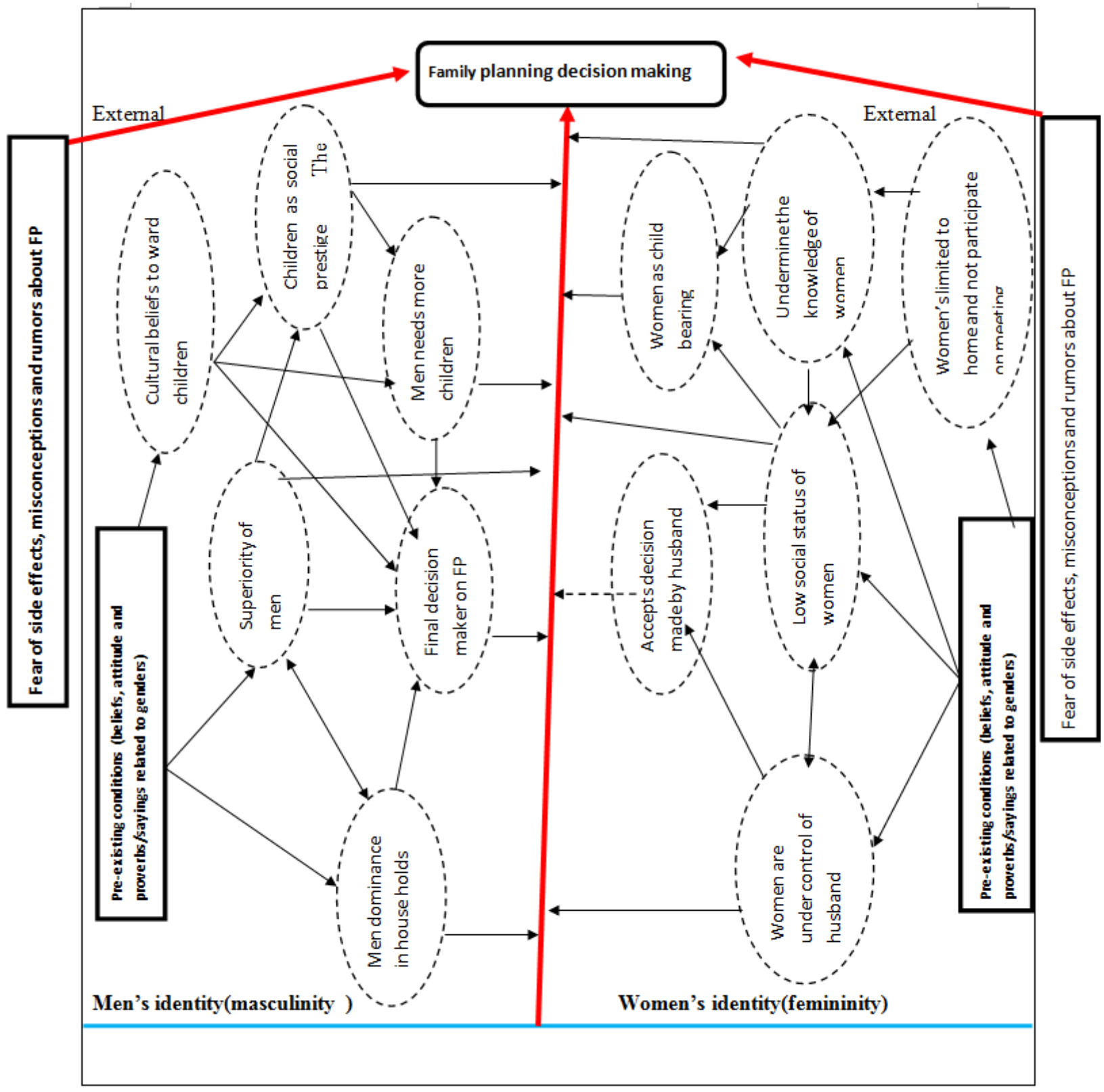

Figure-2. Conceptualization of gender norms effects on family panning-decision making among married men and women.

\section{Discussion}

The aim of this study was to explore gender norms influence on family planning decision making among married men and women in Rural Kebeles of Ethiopia. With this broad question, the purpose was to identify what men's identity (masculinity) means for men and women's identity (femininity) means for women, what are the preexisting conditions for the existence of those gender norms, how gender norms are influence couple communications and decision making power, childbearing and family size was the main purpose for this study.

From early of birth date, at family level ways of expressing their happiness when they got son and daughter was very different. At that time (time of birth) the main issue was the sex of newborn baby. Such thoughts in community play crucial role for the developments of gender norms (masculinity and femininity) identity in community.

Related with cultural beliefs men are expected to have large families which was considered as social prestige or popularity in community. That is why sons are more preferred by community than daughters.

The findings indicate that different gender norms influence FP use in various ways. Some studies emphasize the importance of influence from men/husband and that in order to get a man's/husband's acceptance of FP use there is a need of better communication between partners (18). However, this study revealed that when a couple could not reach an agreement related to FP use, the husband's decision tended to be prioritized because of a gender-based power 
imbalance/men's decision making power. A case study regarding gender norms and decision-making in Tanzania reports a similar situation in which almost all men and women discussed family planning, but a gender inequality was still present in the execution of decisions with family planning; the final decision maker being male(19).

Moreover, men are in many cases found to be more pronatalistic than women, which is considered an obstacle to contraceptive use(20). In such cases the power imbalance between genders will to a large extent prevent women from using contraceptives. However, a power imbalance between genders can also cause other trends. In a study from Tanzania, reported that men forced their wives to use contraceptives (21). This may occur when the idea of family planning is becoming increasingly accepted.

These two different approaches are apparently contradictive; however, they are both a product of a common gender-imbalanced relationship as well as a tendency of a change of views on the acceptance of contraceptives. This finding also showed that there is an example of husband that made his wife use FP, even if the wife does not wants to use it, but where the gender-imbalanced/decision making power of men relationship made it difficult for this wife to refuse.

This study also found that gender norms influenced the opportunity to get information on family planning. These gender norms, implying that women should stay at home and work, hindered women from attending the meetings conducted by kebele women federations and HEWs. There were also examples of social sanctions such as people talking negatively about the women who attended the meetings.

(22) Found that significant proportions of study participants in Nigeria reported couple communication on $\mathrm{RH}$ issues and concluded that this was a sign of an emerging egalitarian society where equity and respect are becoming norms. But the finding of this study found that couple communication on $\mathrm{RH}$ issue and family planning was not common in community among married men and women.

Even though husband and wife are communicate on different issue of their life but no emphasize was given for $\mathrm{RH}$ issue and family planning. In many countries, traditional male and female gender roles deter couples from discussing sexual matters which is ultimately contribute to poor reproductive health among both men and women (23).This study also found that in the community for women communicating on $\mathrm{RH}$ issue with men was considered as shame.

The study clearly shows that fears of side effects related to the use of FP methods prevented people from using them. The interviews revealed many misconceptions and rumors related to side effects of FP methods, regardless of whether people had ever used FP methods or not. Many women are not intended to use the methods due to those factors, on other hand the husbands also prevents their wives from using the methods due to those factors like fears of side effects on women, misconceptions and rumors about the methods.

From the study it was seen that gender norms (masculinity and femininity) identity have an influence on family planning decision making among married men and women. Due to men's dominance in households, their power for final decision maker on family planning decision and men's needs for more children due to cultural beliefs of children as social prestige it is very difficult for women to use family planning when they intended to use it. It is only possible for married women/wives to use family planning when she got consent of their husband.

In many developing African countries, men are often the primary decision-makers about sexual activity, fertility, and contraceptive use (12).which was similar with the finding of this study.

The finding of the study shows that beyond its advantage, secretly using family planning by the women/wives has great consequence on the life of households, especially on women. The consequence starts by warning up to divorce. Also different physical injury was also happen to women while they are torched by their husbands.

\section{Conclusion}

Many of cultural beliefs, attitude toward gender, proverbs/sayings related with gender are identified as preexisting conditions for the existence of those gender norms. From this study religion was found that it has no role in the existence of gender norms in the community.

The study shows that different gender norms in the community were obstacles for family planning utilization in the community. Those gender norms directly or by complement with each other acts as the barriers of FP utilizations. Decision making power of men/husbands on family planning (needs for his consent by women/wives), seeing children as social prestige due to cultural beliefs, low status of women in community, undermining knowledge of women, limiting responsibility of women/wives to home, dominance of men/husbands on households, etc are affects directly or by complement with each other the family planning decision making among married men and women.

The result of this study shows that all those elements are intricately related to with one another, subsequently, family planning decision making among married men and women are affected by complex issue and leads to disagreement or interest of gap between the couples.

Due to men dominance at house level and other related factors roles of women on family planning decision making was limited to accept the idea of their husband. Furthermore due to men's power of decision making it was finalized based on the interest of men/husband.

From the study the coupe communication on issue of $\mathrm{RH}$ and family planning was not common even though they are communicate on other issue of their life, no consideration was given for issue of RH and FP.

The findings of this study shows that the issue of gender norms were not given emphasize in the community. furthermore has it was highly deep rooted with daily life of the community awareness which have no sustainability and only done by woreda women's and children affairs did not 
bring change in community.

From my study I found that even if there some changes were in community related with some awareness given through woreda women's and children affairs on women's right or equality, still those identified gender norms are highly exercised in daily life the community.

\section{Recommendation}

Gender norms are highly grounded and deep rooted in everyday life of community. Changes on this issue only occur over a long period. Interventions on this issue should be making a sustainable effort to initiate awareness creation, discussion with community, even at individual level. Men needs to given the opportunity, free and safe forum, to talk about their roles as men in community and household level, its pressure and its possible solution to those gender related problems on family planning decision making.

Family planning messages and intervention should consider gender norms, engage both men and women and encourage equitable decision making. BCC and IEC program targeting to family planning at different levels of government should give consideration and attention for gender norms in the community.

\section{Limitation of the Study}

May be social desirability bias, due to data collection methods of face-to -face interview and FGD

\section{References}

[1] Central Statistical Agency [Ethiopia] and ORC Macro. Ethiopia Demographic and Health Survey 2005. Addis Ababa, Ethiopia, and Calverton, Maryland, USA: Central Statistical Agency and ORC Macro,2006.

[2] World health organization. Dept. of Health and Human Services, Office of Population Affairs: Available At: $<$ http://www.who.int/mediacentre/factsheets/fs351/en/>

[3] Population Family Planning and the Future of Africa Population Family Planning and the Future of Africa. world watch 2004 Published in world watch magazine. Available at: World Watch Magazine $<\mathrm{http} / /$ www.worldwatch.org/epublish/1>, September/October 2004, Volume 17, No. 5.

[4] Federal Democratic Republic of Ethiopia. Family Planning Extension Package. Addis Ababa,September,2003.

[5] Central Statistical Agency (CSA) and ICF International. Ethiopia Demographic and Health,Survey 2011. Addis Ababa, Ethiopia and Calverton, MD,USA :CSA and ICF International; 2012. 430 p.2012.

[6] Oladeji D. socio-cultural and norms factors influencing family planning choices among couples in Ibadan metropolis,Nigeria. ol abisi onabanjo university,ago- iwoye,Nigeria,. 2008.
[7] Gill R. and Stewar DE. Relevance of Gender-Sensitive Policies and General Health Indicators to Compare the Status of South Asian Women's Health.: women's Health Issues 2011 21(1): (12-18.)2012.

[8] Dennis P. Betemariam B. Asefa H. Household organization women's autonomy and contraceptive behavior in southern Ethiopia. Studies in family planning.2002,30:302-314.

[9] Jane Ch. Interventions linking gender relations and violence with reproductive health and HIV: rationale, effectiveness and gaps. 2006.

[10] Evolving men. Initial Results from the International Men and Gender Equality Survey, Men and gender equality policy project,2009.

[11] Guttmacher Institute and International Planned Parenthood Federation. Facts on Satisfying the Need for Contraception in Developing Countries.New York: Guttmacher Institute,2010.

[12] Hollerbach P. Powers in families, communication and fertility decision-making. Population and Environment, . (2001);3 (2): :146-71.

[13] Changing priorities in an era of social transformation and globalization. Belgium, International Union for the Scientific Study of Population; 2002.

[14] Dennis P. Betemariam B. Asefa H. Household organization women's autonomy and contraceptive behavior in southern Ethiopia. Studies in family planning; 2002, 30:302-14.

[15] Kim Y. Kols A. Mudieke S. Informed choice and decisionmaking in family planning counseling in Kenya. International Family Planning Perspectives 2002 ;(24(1): 4-11, 42).

[16] Public Choices. Private Decisions:. Sexual and Reproductive Health and the Millennium Development Goals.

[17] Akinrinola B. Sasheela S. Couples Fertility and contraception Decision Making in Developing Countries: Hearing the Man's Voice. . International Family Planning perspective,2004

[18] A. Berhane, Biadgilign, Amberbir, Morankar \& Deribe, family planning utilization among rural community, southern Ethiopia. (2010).

[19] Schuler S. R. Rottach E. \&Mukiri P . Gender norms and family planning Decision-making in Tanzania: a qualitative study. Journal of Public Health in Africa, 2(2), (2011).

[20] Moser. R. M.: Reproductive health issue for refugees in Latin America. Personal Communication, April 22 (2001).

[21] Oyediran.K. Isiugo-Abanihe, Uche C.: Bankole. A. Correlates of spousal communication on fertility and family planning among the Yoruba of Nigeria. Journal of Comparative Family Studies (2006).37(3): p41-61.

[22] Greene. M. and Biddlecom. A.: Absent and Problematic Men: Demographic Accounts of Male Reproductive Roles. New York: Population Council, (1997).

[23] Hull. T.: Fertility Regulation and Institutional Influences. Cultural influence on fertility decision styles. Determinants of Fertility in Developing Countries,. New York (2000). 